\title{
The fate of the foreskin
}

Martin A. Koyle

Hospital for Sick Kids, Toronto, ON, Canada

Cite as: Can Urol Assoc J 2017 Dec. 1; Epub ahead of print. http://dx.doi.org/10.5489/cuaj.5075

Published online December 1, 2017

$* * *$

The fate of the foreskin has had a profound effect on humanity throughout the ages. Although circumcision predated monotheist religion by thousands of years, likely as a socially mandated rite, the acceptance of circumcision as being an order from God to the Jews as written in Genesis has perpetuated this procedure for over 3000 years.

Circumcision itself remains a controversial subject that polarizes its supporters and refuters. Data can be used by both camps to argue one way or the other, either pro or con. Willard Goodwin, the legendary Chair of Urology at UCLA once stated that if the energy wasted on arguing the merits of circumcision could be channelled into solving more universal problems, the world would be a better place. He argued that the controversy regarding circumcision was no different than that surrounding whether one should or shouldn’t crop a Cocker Spaniel's tail!

As someone who has practiced on both sides of the border, I must admit there are huge differences as to how the newborn penis is dealt with. In the U.S., where at least $60 \%$ of newborns are circumcised, circumcision and surgery related to the consequences of circumcision, made up $>40 \%$ of my surgical practice. In order to maintain a practice there, I actually tried to attract those patients. In Canada, or at least in Ontario where elective circumcision isn't covered by the provincial health insurance, our clinics are inundated by unnecessary referrals related to basic care of the prepuce. The majority of these referrals are reflective of the fact that our primary care colleagues spend no time with urologists and/or that we are unable to educate them properly about the simplest things, such as smegma, adhesions, when the foreskin retracts, what metal stenosis truly is, or when and why steroid cream might be indicated in a given patient. Newborn circumcision is largely performed by non-urologists, many of whom learn to do it on the job. Although the authors of these excellent guidelines published in this month's CUAJ suggest for the most part that circumcision is a safe procedure associated with low complication rates, I am convinced that the complication rate is far higher than reported in the literature. In my own career, anecdotally, I have seen deaths from neonatal 


\section{Koyle}

Foreskin

circumcision secondary to hemorrhage and to necrotizing fasciitis, amputated glans and penis shaft, not to mention all the other common secondary problems related to circumcision, simple and complex. Like any other procedure, it requires training and practice, judgment, and knowledge of the indications and contraindications, not to mention proper analgesia and equipment. As a largely elective procedure, for societal and religious reasons alone, circumcision will continue to be practiced, regardless of payer or medical data that is published regarding its benefits and risks. It is important in single payer system like we have in Canada, where quality and patient safety are promoted, that a "small" specialty like ours not only publishes thoughtful guidelines such as this, but takes the initiative to assure that our non-urology colleagues who perform most newborn circumcisions and care primarily for those with an intact prepuce, have more than a basic knowledge of the organ that they are caring for. 